\title{
Adenosine Generated in the Bone Marrow Niche Through a CD38-Mediated Pathway Correlates With Progression of Human Myeloma
}

\author{
Alberto L Horenstein, ${ }^{1,2}$ Valeria Quarona, ${ }^{1}$ Denise Toscani, ${ }^{3}$ Federica Costa, ${ }^{3}$ Antonella Chillemi, ${ }^{1}$ \\ Vito Pistoia, ${ }^{4}$ Nicola Giuliani, ${ }^{3}$ and Fabio Malavasi ${ }^{1,2,5}$
}

${ }^{1}$ Laboratory of Immunogenetics, Department of Medical Sciences, University of Torino, Torino, Italy; ${ }^{2}$ CeRMS, University of Torino, Torino, Italy; ${ }^{3}$ Myeloma Unit, Department of Clinical and Experimental Medicine, University of Parma, Parma, Italy; ${ }^{4}$ Laboratory of Oncology, Istituto Giannina Gaslini, Genova, Italy; and ${ }^{5}$ Transplantation Immunology, Città della Salute e della Scienza, Torino, Italy

\begin{abstract}
Human myeloma cells express CD38 at high levels and grow in hypoxic niches inside the bone marrow. Myeloma cells respond to hypoxia with metabolic changes leading to aerobic glycolysis, thus reducing adenosine triphosphate (ATP) and increasing $\mathrm{NAD}^{+}$. Our hypothesis is that these conditions favor the enzymatic pathways involved in the production of adenosine in the niche. Within the niche, $\mathrm{NAD}^{+}$is able to activate a discontinuous adenosinergic pathway that relies upon CD38, CD203a and CD73 or TRACP, according to the environmental $\mathrm{pH}$. The observed variability in adenosine concentrations in bone marrow aspirates is a result of the interactions taking place among myeloma and other cells in the bone marrow niche. A pilot study showed that adenosine profiles differ during disease progression. Adenosine levels were significantly higher in the bone marrow plasma of patients with symptomatic myeloma and correlated with ISS staging, suggesting that adenosine is produced in the myeloma niche at micromolar levels by an ectoenzymatic network centered on CD38. Adenosine levels increase with disease aggressiveness, a finding that supports adenosine as a potential marker of myeloma progression.
\end{abstract}

Online address: http://www.molmed.org

doi: $10.2119 / \mathrm{molmed} .2016 .00198$

\section{INTRODUCTION}

Multiple myeloma (MM) is characterized by accumulation of plasma cells (PC) in the bone marrow (BM) (1). This proliferation of malignant $\mathrm{PC}$ is driven by an endless loop: myeloma-secreted products stimulate specialized cells in the BM myeloma cell niche, which in turn release soluble factors that modulate tumor cell proliferation and immune response (2). How these complex interactions influence myeloma cell growth and disease progression within the $\mathrm{BM}$ milieu is only partly known. What is clear is that MM cells exploit local metabolic reprogramming and the induction of hypoxic conditions as their main mechanisms of immune escape $(3,4)$. Unlike normal PC, MM cells respond to hypoxia with a metabolic shift leading to aerobic glycolysis (the Warburg effect), to cope with the growing need for energy required by neoplastic proliferation (5).

As a consequence, the tumor environment contains high levels of extracellular nucleotides (ATP, NAD ${ }^{+}$), which not only serve intracellularly as building blocks for cell division and energy metabolism, but

Address correspondence to Alberto L Horenstein, Laboratory of Immunogenetics, Department of Medical Sciences, University of Torino, Via Santena 19, Torino 10126, Italy. Phone: + 39-011-696-1734; Fax: +39-011-696-6155; E-mail: alberto.horenstein@unito.it. Submitted September 22, 2016; Accepted for Publication September 23, 2016; Published Online (wWw.molmed.org) October 13, 2016.

Jivivi

Feinstein Institute for Medical Research Northwell Health

have also been recognized as intercellular communicators and signal transducers (6). Indeed, nucleotides and their degradation products are believed to modulate communication between myeloma and normal cells, contributing to the immunocompromised state of MM patients (7).

Nucleotides are extruded from inside the cells through active channeling mechanisms and either serve as signaling molecules by binding to purinergic type $\mathrm{P} 2$ receptors or are metabolized into intermediate nucleotides that are subsequently broken down to adenosine (ADO) by cell surface proteins endowed with an enzymatic domain (for example, ectoenzymes) $(8,9)$.

Extracellular ATP, the primary substrate of the adenosinergic ectoenzymes, is first hydrolyzed by the ecto-nucleoside triphosphate diphosphohydrolase CD39. The adenosine monophosphate (AMP) molecules produced by CD39 can be further hydrolyzed by the 5'-nucleotidase CD73, thereby generating ADO. A recent 
finding is that ADO may also be produced from $\mathrm{NAD}^{+}$by an axis centered on the $\mathrm{NAD}^{+}$-metabolizing CD38 generating adenosine diphosphate ribose (ADPR) $(9,10)$. The pyrophosphatase/phosphodiesterase CD203a is capable of hydrolyzing both $\mathrm{NAD}^{+}$and ADPR to produce AMP. Accordingly, extracellular $\mathrm{NAD}^{+}$flows through an ectoenzymatic cascade that culminates in ADO formation through the conversion of AMP by CD73 (9). In turn, ADO can bind to specific purinergic $\mathrm{P} 1$ receptors and elicit immunosuppressive signals by modulating cAMP levels, and then either be inactivated at the cell surface by an ADA/CD26 complex that converts ADO into inosine, or internalized by nucleoside transporters $(11,12)$. ADO immunosuppressive activity inside the BM niche may derive from activation of hypoxia-regulated genes and secretion of their products (for example, HIF- $1 \alpha$, CD73, or AMPK) $(4,12)$ resulting in a general anergic status, which promotes tumor survival.

The myeloma BM niche is a good testing ground for assessing the functionality of a connection between ectoenzymes and their substrates. Accordingly, this work provides indepth analysis of the role of CD38 in the production of ADO in the BM niche of MM patients, highlighting that the products of the enzymatic reactions derived from intense in situ cross-talk among different cells are conditioned by local metabolic events. Further conjecture is that CD38 and related ADO production may reflect disease progression from premalignant stages to overt MM $(1,13)$. Proof of concept was provided by the direct correlation between the level of immunosuppressive ADO detected in BM plasma samples derived from myeloma patients and the aggressiveness of their disease.

\section{MATERIALS AND METHODS}

\section{Patients}

A cohort of 39 patients (17 male and 22 female) with plasma cell disorders included five patients with monoclonal gammopathy of undetermined significance (MGUS) [female $=80 \%$, male $=$ $20 \%$; median age: 63 years (range: $44-77$ )], 13 with smoldering myeloma (SMM) [female $=31 \%$, male $=69 \%$, median age: 69 years (range: $42-87)$ ], 21 with active MM, including 16 who were newly diagnosed $[$ female $=69 \%$, male $=31 \%$; median age: 71 years (range: 53-86); International staging system (ISS): $44 \%$ stage I-II and 56\% III; adverse FISH: 44\%] and five relapsed $\mathrm{MM}$ [female $=80 \%$, male $=$ 20\%, median age: 77 years (range: 69-90); ISS: 20\% stage I-II and 80\% III; adverse FISH: 40\%]. Adverse cytogenetic/fluorescence in situ hybridization (FISH) refers to unfavorable $\mathrm{IgH}$ translocations $[\mathrm{t}(4 ; 14)$ or $\mathrm{t}(14 ; 16)], 17 \mathrm{p} 13 \mathrm{del}$ and/or 1q21 gain. One Waldenström macroglobulinemia was included in the analysis. The clinical characteristics of the cohort are summarized in Table 1. The Institutional Review
Board (University of Parma) approved the study protocols and the patients provided a written informed consent (Declaration of Helsinki).

\section{Chemicals}

$\mathrm{NAD}^{+}, \mathrm{NADP}$, nicotinamide guanine dinucleotide $\left(\mathrm{NGD}^{+}\right), \mathrm{ADPR}, \mathrm{ATP}, \mathrm{AMP}$, ADO, adenosine deaminase (ADA), sodium phosphate, phosphoric acid and acetonitrile (ACN, HPLC-grade reagent) were all from Sigma-Aldrich, as were kuromanin (CD38 inhibitor), $\alpha, \beta$ methylene ADP (APCP, CD73 inhibitor), erythro-9-(2-hydroxy-3-nonyl)-adenine (EHNA, adenosine deaminase inhibitor), deoxycoformycin (DCF, adenosine deaminase inhibitor), levamisole (alkaline phosphatase inhibitor) and dipyridamole (DYP, nucleoside transporter inhibitor). Milli-Q water was employed throughout the study (Millipore).

Table 1. Main clinical and molecular characteristics of the cohort of 21 patients with symptomatic (MM).

\begin{tabular}{|c|c|c|c|c|c|c|c|c|c|}
\hline PT & Sex & Age & Diagnosis & State & $\begin{array}{l}\text { High bone } \\
\text { disease }\end{array}$ & Osteolysis & High risk & $\begin{array}{l}\text { Adenosine } \\
(\mu \mathrm{mol} / \mathrm{L})\end{array}$ & ISS \\
\hline A.MG & $\mathrm{F}$ & 55 & MM & $D$ & YES & YES & YES & 22.00 & III \\
\hline A.M. & $\mathrm{F}$ & 69 & MM & $\mathrm{R}$ & YES & YES & NO & 74.20 & III \\
\hline B.FL. & $M$ & 70 & MM & $D$ & $\mathrm{NO}$ & NO & $\mathrm{NO}$ & 69.88 & $\|$ \\
\hline B.FA. & $M$ & 57 & MM & $D$ & YES & YES & $\mathrm{NO}$ & 62.17 & I \\
\hline B.R. & $F$ & 71 & MM & R & YES & YES & - & 110.28 & III \\
\hline C.M. & $\mathrm{F}$ & 74 & MM & $D$ & $\mathrm{NO}$ & YES & YES & 119.89 & III \\
\hline C.MG. & $\mathrm{F}$ & 60 & MM & $D$ & NO & NO & $\mathrm{NO}$ & 45.37 & $\|$ \\
\hline C.I. & $\mathrm{F}$ & 74 & MM & $D$ & $\mathrm{NO}$ & $\mathrm{NO}$ & YES & 55.61 & III \\
\hline G.A. & $\mathrm{F}$ & 76 & MM & $D$ & $\mathrm{NO}$ & YES & - & 56.96 & $\|$ \\
\hline M.A. & $\mathrm{F}$ & 76 & MM & $D$ & YES & YES & $\mathrm{NO}$ & 62.37 & 1 \\
\hline M.MV. & $\mathrm{F}$ & 86 & MM & $R$ & YES & YES & $\mathrm{NO}$ & 39.26 & $\|$ \\
\hline M.E. & $M$ & 90 & MM & $R$ & YES & YES & - & 165.10 & III \\
\hline M.U. & $M$ & 57 & MM & $D$ & YES & YES & NO & 129.78 & III \\
\hline M.G. & $M$ & 65 & MM & $D$ & $\mathrm{NO}$ & $\mathrm{NO}$ & YES & 62.73 & III \\
\hline M.M. & $F$ & 69 & MM & $D$ & NO & YES & - & 39.26 & I \\
\hline O.C. & $F$ & 86 & MM & $D$ & YES & YES & YES & 78.21 & III \\
\hline S.M.G. & $M$ & 53 & MM & $D$ & YES & YES & YES & 113.00 & III \\
\hline V.F. & $\mathrm{F}$ & 77 & MM & $D$ & $\mathrm{NO}$ & $\mathrm{NO}$ & NO & 155.23 & III \\
\hline X.I. & $\mathrm{F}$ & 79 & $\mathrm{MM}$ & $D$ & YES & YES & YES & 210.84 & III \\
\hline Z.EC. & $\mathrm{F}$ & 77 & MM & $\mathrm{R}$ & YES & YES & - & 45.99 & III \\
\hline Z.F. & $\mathrm{F}$ & 68 & MM & $D$ & YES & YES & $\mathrm{NO}$ & 107.81 & $\|$ \\
\hline
\end{tabular}

Analysis of MM patients included: (i) International staging system (ISS); (ii) Presence of $\geq 3$ osteolytic lesions or fractures are defined as high bone disease; (iii) Patients (PT) with either del(17p), $\mathrm{t}(4 ; 14)$ or $\mathrm{t}(14 ; 16)$ were considered to be at high cytogenetic risk and at standard risk otherwise; (iv) Adenosine concentrations ( $\mu \mathrm{mol} / \mathrm{L}$ ) measured at diagnosis (D) or relapse (R). 


\section{Antibodies and Cytofluorography}

The monoclonal antibodies (mAbs) used in this study were anti-CD38 (clone IB4), anti-CD203a (PC-1, clone 3E8, kindly provided by J Goding), anti-CD73 (clone CB73), anti-CD26 (clone BT5.9), anti-HLA Class I (clone 01.65) and anti-HLA Class II (clone $\mathrm{Ab}$ 2.9), which were locally produced and purified in-house by 2-step HPLCchromatography (14). Anti-CD39 mAb was from eBioscience. AcZon provided the fluorescent labeling of the distinct mAbs. Fluorescein isothiocyanate (FITC) conjugated goat-anti rabbit Ig (Jackson Immuno-Research Laboratories), donkey anti-goat Ig (Thermo Fisher Scientific) and $\mathrm{F}\left(\mathrm{ab}^{\prime}\right)_{2}$ goat anti-mouse IgG + $\operatorname{IgM}[\mathrm{G} \alpha \mathrm{M} \operatorname{Ig}(\mathrm{G}+\mathrm{M})$ FITC] (Jackson Immuno-Research Laboratories) were used as secondary reagents.

Indirect immunofluorescence tests were performed on cells washed in phosphate buffered saline (PBS) containing 1\% bovine serum albumin (BSA) $+\mathrm{NaN}_{3}$ and incubated with primary mAbs for $1 \mathrm{~h}$ at $4^{\circ} \mathrm{C}$. Cells were then washed twice and incubated with FITC-conjugated anti-mouse $\mathrm{Ab}$ for $30 \mathrm{~min}$ at $4^{\circ} \mathrm{C}$. The samples were washed, resuspended in PBS and acquired on a FACSort flow cytometer (Becton-Dickinson) using CellQuest Software (Becton-Dickinson). Data were analyzed using FlowJo Software (TreeStar).

\section{Immunohistochemistry}

BM biopsies obtained from myeloma patients were fixed in formaldehyde, paraffin-embedded, and cut into $2.5 \mu \mathrm{m}$ tissue sections. After antigen retrieval in citrate buffer $\left(\mathrm{pH} 6\right.$ at $98^{\circ} \mathrm{C}$ for $30 \mathrm{~min}$, followed by treatment with $6 \% \mathrm{H}_{2} \mathrm{O}_{2}$ for $7 \mathrm{~min})$, sections were incubated $(1 \mathrm{~h}$, room temperature) with polyclonal and $\mathrm{mAbs}$ diluted in PBS $+1 \%$ BSA + $0.1 \% \mathrm{NaN}_{3}$. The antibodies used were murine anti-CD38 mAb and polyclonal rabbit anti-CD38 [1:1,500] (Sigma); murine anti-CD73 mAb (clone CB73) and polyclonal rabbit anti-CD73 [1:1,000] (Sigma); polyclonal rabbit anti-CD39 [1:5,000] (Sigma); murine anti-CD203a mAb and polyclonal goat anti-CD203a [1:500]
(Thermo Scientific). After rinsing in PBS 1x-Tween-20, antigen binding was revealed using the EnVision HRP detection kit (Dako). Mayer's hematoxylin was used as the nuclear counterstain. Irrelevant isotype-matched murine Ig for mAbs and normal sera of rabbit and goat origin were used as negative controls. Samples were evaluated by light microscopy and read by two independent observers. Tartrate-resistant acid phosphatase (TRACP) was evaluated using a leukocyte acid phosphatase kit (Sigma-Aldrich) following the manufacturer's instructions.

\section{HPLC Analyses}

Chromatography was performed with an HPLC (Beckman Coulter) fitted with a reverse-phase column (Syn-

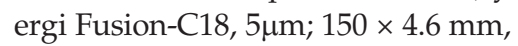
Phenomenex BO). Nucleotides and nucleosides were separated using a mobile-phase buffer [ $0.020 \mathrm{~mol} / \mathrm{L}$ citric acid, $0.025 \mathrm{~mol} / \mathrm{L}$ sodium phosphate, adjusted with phosphoric acid to a $\mathrm{pH}$ of 4.5 , and $8 \%$ acetonitrile (ACN)] for $\leq 12 \mathrm{~min}$ at a flow rate of $0.8 \mathrm{~mL} / \mathrm{min}$. Ultraviolet (UV) absorption was measured at $260 \mathrm{~nm}$. HPLC-grade standards used to calibrate the signals were dissolved in Hank's Balanced Salt Solution (HBSS) (Sigma), pH 7.2, $0.2 \mu \mathrm{m}$-filtered and injected in a volume of $15 \mu \mathrm{L}$. The retention times $\left(\mathrm{R}_{\mathrm{t}}\right.$, in $\left.\mathrm{min}\right)$ of standards were: $\mathrm{AMP}, 2.35$; $\mathrm{NAD}^{+}, 3.0$; $\mathrm{NGD}^{+}, 3.2$; $\mathrm{ADPR}$, 5.3; NAM, 7.1, and ADO, 8.1; using a $\mathrm{R}_{\mathrm{t}}$ window of $\pm 5 \%$. Peak integration was performed using the Gold software (Beckman Coulter). Quantitative measurements were inferred by comparing the peak area of samples with calibration curves for peak areas of each standard compound.

\section{Nucleotide Consumption and ADO Production}

Nucleotide consumption by cells $\left(2 \times 10^{6}\right.$ cells $\left./ \mathrm{mL}\right)$ and ADO production were evaluated in HBSS (Sigma), containing $\mathrm{NAD}^{+}, \mathrm{NGD}^{+}, \mathrm{ATP}$ or AMP (100 $\mu \mathrm{mol} / \mathrm{L})$ in the presence of $100 \mu \mathrm{L} / \mathrm{mL}$ of a STOP Solution $(100 \mu \mathrm{mol} / \mathrm{L}$ EHNA, $10 \mu / \mathrm{mol} / \mathrm{L}$ DYP, $30 \mu \mathrm{g} / \mathrm{mL}$ levamisole and $10 \mu \mathrm{mol} / \mathrm{L} \mathrm{DCF}$ ) (Sigma).
After centrifugation $\left(700 g ; 5 \mathrm{~min}\right.$ at $\left.4^{\circ} \mathrm{C}\right)$, supernatants were collected and diluted 1:2 with ACN (Sigma) at $4^{\circ} \mathrm{C}$ to stabilize ADO. Samples were centrifuged $(13,000 g, 5 \mathrm{~min}$ at $4^{\circ} \mathrm{C}$ ) and supernatants evaporated by Speed Vac (Eppendorf), reconstituted in High Pressure Liquid Chromatography (HPLC) water and assayed by HPLC. The nature of the ADO peak was confirmed by an enzymatic peak shift assay after incubation with adenosine deaminase (ADA, $10 \mathrm{IU} / \mathrm{mL}$ ), which led to a reduction $(63 \% \pm 15)$ of the ADO signal (9).

\section{Cells and Cell Lines}

Primary MM cells were isolated using anti-CD138 mAb-coated magnetic beads (Miltenyi). The LP-1 cell line was stabilized locally from plasma cell leukemia (15). The osteoblast-like SAOS-2 cell line (American Type Culture Collection) was cultured in Roswell Park Memorial Institute (RPMI) $1640+5 \%$ FCS, glutamine ( $2 \mathrm{mmol} / \mathrm{L})$, kanamycin $(50 \mu \mathrm{g} / \mathrm{mL})$, penicillin $(100 \mathrm{U} / \mathrm{mL})$ and streptomycin (100 $\mu \mathrm{g} / \mathrm{mL}$ ) (all from Sigma), while the HS-5 human bone marrow stromal cell line (American Type Culture Collection) was maintained in Iscove's Modified Dulbecco's Medium (IMDM) (Sigma) + $10 \%$ fetal calf serum (FCS).

\section{Osteoblast and Osteoclast Differentiation}

Osteoblasts were obtained from peripheral blood mononuclear cells (PBMC) isolated from BM aspirates from patients with myeloma after using a Ficoll-Paque (GE Healthcar) gradient centrifugation. Cells were resuspended in $\alpha$-MEM medium (Gibco life technologies) $+10 \%$ FCS and plated in 24-well plates. Confluent adherent cells were treated with $\beta$-glycerol phosphate $(10 \mathrm{mmol} / \mathrm{L})$, ascorbic acid $(50 \mu \mathrm{g} / \mathrm{mL})$ and dexamethasone (100 nmol/L). Twenty-eight days later, mineralization was assayed by Alizarin Red (2\%) staining, all purchased from Sigma.

Differentiated osteoclasts were obtained after transferring cells in suspension to other plates $\left(1.5 \times 10^{6}\right.$ cells $/ 500 \mu \mathrm{L}$ medium) and exposing 
them to $25 \mathrm{ng} / \mathrm{mL}$ of recombinant human macrophage colony- stimulating factor (rhM-CSF) (PeproTech, London, $\mathrm{UK})$, followed by rhM-CSF (25 ng/mL) and receptor activator of nuclear factor kappa-B ligand (RANKL) (30 ng/mL, PeproTech). After $21 \mathrm{~d}$, mature osteoclasts ( $\geq 3$ nuclei) were identified as TRACP (tartrate-resistant acid phosphatase) positive cells.

\section{Cell Co-Cultures}

Cells $\left(5 \times 10^{5}\right.$ cells $\left./ \mathrm{mL}\right)$ co-cultured in 24-well plates $\left(15 \mathrm{~min}\right.$ at $\left.37^{\circ} \mathrm{C}\right)$ with $100 \mu \mathrm{L} / \mathrm{mL}$ STOP Solution, were treated with different substrates (ATP, AMP or $\mathrm{NAD}^{+}$, all $100 \mu \mathrm{mol} / \mathrm{L}$ ). After $30 \mathrm{~min}$, supernatants were collected in a tube containing acetonitrile (ACN; $1: 2$, at $4^{\circ} \mathrm{C}$ ), centrifuged $\left(13,000 \mathrm{~g}, 5 \mathrm{~min}\right.$ at $\left.4^{\circ} \mathrm{C}\right)$ and analyzed by HPLC or stocked at $-80^{\circ} \mathrm{C}$.

\section{Statistical Analyses}

In vitro experiments were performed in triplicate and repeated at least twice; a representative experiment (mean \pm SD) was selected for the figures, except when otherwise specified. Statistical analysis was performed using the Student $t$ or Mann-Whitney $U$ tests. Statistical evaluations were performed using GraphPad Prism software. For all analyses, differences were considered significant at $P<0.05\left({ }^{*} P<0.05,{ }^{* *} P<0.01\right.$ and $* * * P<0.001)$ versus control and ns for not significant.

\section{RESULTS}

\section{Adenosine in Aspirates from the BM Myeloma Niche Obtained from MM Patients}

The first steps of this work were to confirm the presence of ADO in plasma obtained from biopsies from patients with MM and to analyze the conditions leading to ADO production. Plasma from BM biopsies was immediately pretreated for the HPLC assay, given the very short half-life of ADO and its rapid uptake by cells of the BM niche.

The BM plasma from MM patients contained different amounts of ADO

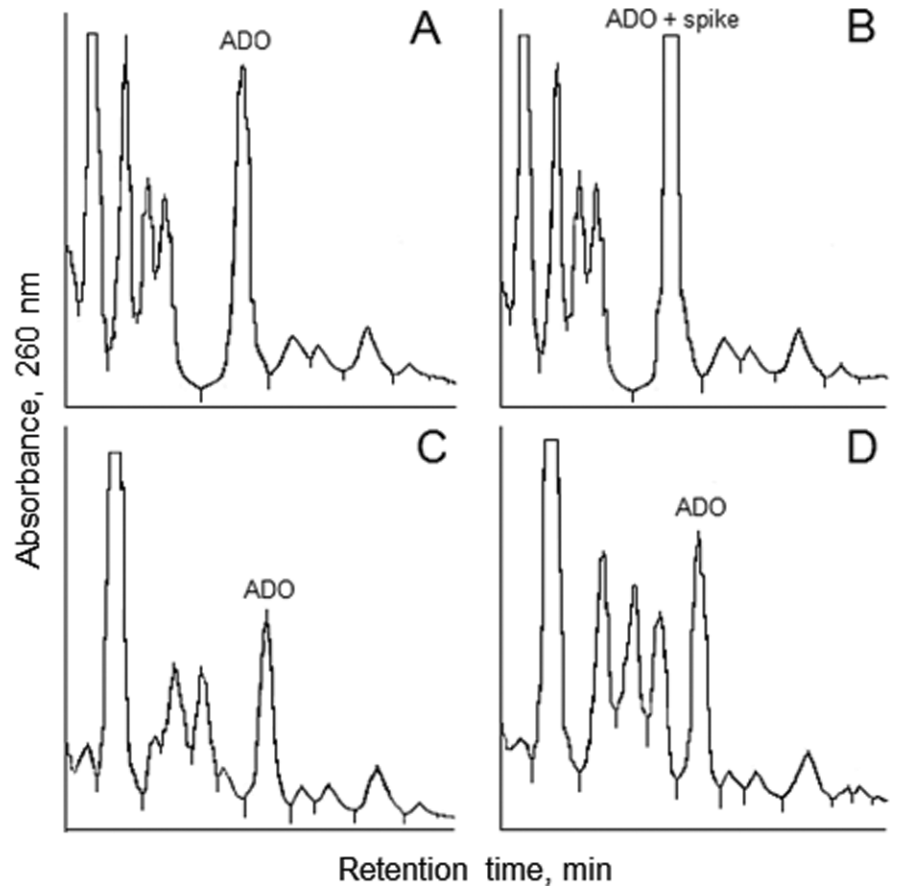

Figure 1. ADO levels in BM plasma obtained from asymptomatic MGUS/SMM and symptomatic MM patients. BM plasma samples were analyzed by HPLC. (A) HPLC profile of a representative $\mathrm{MM}$ patient $(X . \mathrm{I} .=210.84 \mu \mathrm{M})$. (B) ADO confirmed by specific standard spiking $(50 \mu \mathrm{mol} / \mathrm{L})$ in the $\mathrm{BM}$ aspirate from a MM patient (X.I). (C-D) Representative ADO HPLC profiles from one patient with MGUS (C) and one with SMM (D).

(Table 1), as calculated from the area under the specific peak of the HPLC profile (Figures 1A, B). ADO levels in aspirates from $M M$ patients $(n=21)$ ranged from high (X.I. $=210.84 \mu \mathrm{mol} / \mathrm{L})$ to low (A.MG. $=22.03 \mu \mathrm{mol} / \mathrm{L}$ ) values, with a mean value of $86.95 \pm 48.52 \mu \mathrm{mol} / \mathrm{L}$ of ADO. Furthermore, median ADO concentrations were not significantly different in MM patients at the time of diagnosis or at relapse (median value $=$ $66.31 \mu \mathrm{mol} / \mathrm{L}$ versus $74.20 \mu \mathrm{mol} / \mathrm{L}$, respectively). ADO levels were lower $(<3.82 \pm 1.81 \mu \mathrm{mol} / \mathrm{L})\left({ }^{* *} P=0.000871\right)$ in the BM plasma fluids from patients presenting with other hematological malignancies, for example, monoclonal gammopathy syndrome (POEMS, $\mathrm{n}=2$ ), extramedullary plasmacytoma (EMP, $\mathrm{n}=1$ ), multiple sclerosis (MS, $\mathrm{n}=1$ ) or acute myeloid leukemia (AML, $\mathrm{n}=4$ ), used as a background reference (not shown). These results indicate that the nucleoside is present at variable levels in BM plasma from MM patients.

\section{Adenosine Generation in the BM Myeloma Niche During MM Progression}

The adenosinergic pathways in the $\mathrm{BM}$ niche may vary during progression from asymptomatic MGUS/SMM to overt MM. This would link ADO levels with various stages of the disease. Adenosinergic activities in MM patients were compared with those in MGUS and SMM patients (Table 2). ADO levels (Figures 1A-D) varied in each group (MGUS range: 42.29-85.90 $\mu \mathrm{mol} / \mathrm{L}$; SMM range: $18.40-87.39 \mu \mathrm{mol} / \mathrm{L}$; MM range: 22.03-210.80 $\mu \mathrm{mol} / \mathrm{L})$. However, the median ADO concentration was significantly higher in MM patients ( $\mathrm{n}=21$; median value $=69.88 \mu \mathrm{mol} / \mathrm{L}$ ) than in the asymptomatic MGUS/SMM patients combined $(\mathrm{n}=18 ;$ median value $=46.43 \mu \mathrm{mol} / \mathrm{L})$ $\left.{ }^{* *} P=0.006603\right)$ and in the SMM patients $(\mathrm{n}=13$; median value $=42.00 \mu \mathrm{mol} / \mathrm{L})$ (**P $=0.005695)$ (Figure 2A). Differences in the ADO levels of MM and MGUS $(\mathrm{n}=5 ;$ median value $=56.70 \mu \mathrm{mol} / \mathrm{L})$ 
Table 2. Characteristics of the cohort of 18 patients with asymptomatic (MGUS and SMM) dyscrasias.

\begin{tabular}{lcccc}
\hline PT & Sex & Age & Diagnosis & $\begin{array}{c}\text { Adenosine } \\
(\mu \mathrm{mol} / \mathrm{L})\end{array}$ \\
\hline D.F. & M & 44 & MGUS & 47.50 \\
D.G. & $\mathrm{F}$ & 52 & MGUS & 60.30 \\
M.L. & $\mathrm{F}$ & 77 & MGUS & 85.90 \\
P.M. & $\mathrm{F}$ & 63 & MGUS & 42.29 \\
R.G. & $\mathrm{F}$ & 63 & MGUS & 56.70 \\
B.M. & $\mathrm{F}$ & 70 & SMM & 18.40 \\
B.G. & $\mathrm{M}$ & 69 & SMM & 50.78 \\
B.S. & $\mathrm{F}$ & 42 & SMM & 87.39 \\
C.E. & $\mathrm{M}$ & 83 & SMM & 51.91 \\
C.N. & $\mathrm{M}$ & 87 & SMM & 28.14 \\
D.C. & $\mathrm{M}$ & 56 & SMM & 86.63 \\
E.G. & $\mathrm{M}$ & 74 & SMM & 34.53 \\
F.G. & $\mathrm{F}$ & 69 & SMM & 34.84 \\
F.E. & $\mathrm{M}$ & 72 & SMM & 39.99 \\
I.D. & $\mathrm{M}$ & 68 & SMM & 73.33 \\
M.G. & $\mathrm{M}$ & 56 & SMM & 42.00 \\
T.F. & $\mathrm{M}$ & 61 & SMM & 45.36 \\
T.E. & $\mathrm{F}$ & 79 & SMM & 32.49 \\
\hline
\end{tabular}

Adenosine are expressed as $\mu \mathrm{mol} / \mathrm{L}$ concentrations. patients were not sufficient to reach statistical significance. Surprisingly, the ADO levels in BM plasma from a Waldenström macroglobulinemia, characterized by plasmocytoid CD38 ${ }^{\text {high }}$ cells (16), were 4.6-fold higher than the median value found in MM patients.

A multivariate (sex, age, diagnosis) statistical analysis was performed on ADO levels detected in all the samples, given the different age and sex distribution among the groups of patients (Table 1/II). No correlation was found between ADO levels and the age or sex of patients; the only statistical differences observed were between groups with different diagnosis.

At diagnosis, the ISS provides three conditions with distinct prognostic significance based on serum albumin and $\beta 2$-microglobulin ( $\beta 2-\mathrm{m}$ ) (17). The possibility of using ADO levels as a biomarker for ISS staging as a complement to serum albumin and $\beta 2-\mathrm{m}$ was evaluated by assembling
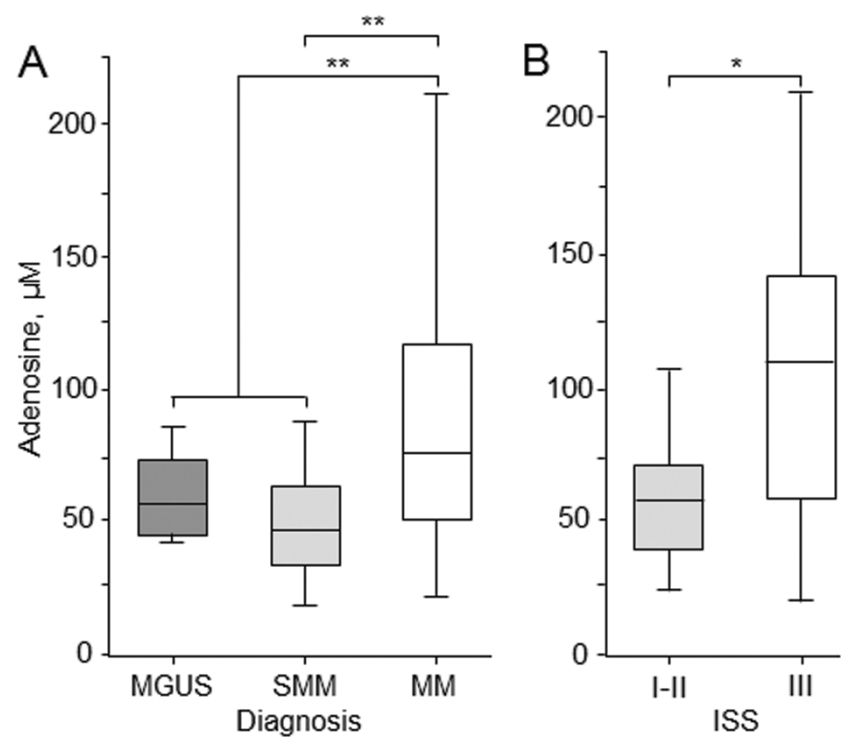

Figure 2. Correlation of ADO levels with diagnosis and ISS stage. HPLC analysis of ADO levels in plasma obtained from BM aspirates from 39 patients at different stages of disease. (A) Median ADO levels from five patients with MGUS (median $=56.70 \mu \mathrm{mol} / \mathrm{L}$; range: $42.29-85.90 \mu \mathrm{mol} / \mathrm{L}$ ), 13 with $\mathrm{SMM}$ (median $=42.00 \mu \mathrm{mol} / \mathrm{L}$; range: $18.40-87.39$ $\mu \mathrm{mol} / \mathrm{L}$ ) and 21 with $\mathrm{MM}$ (median $=69.88 \mu \mathrm{mol} / \mathrm{L}$; range: $22.00-210.84 \mu \mathrm{mol} / \mathrm{L}$ ). (B) ADO levels in BM plasma from symptomatic MM patients, compared by ISS staging. Median ADO levels from eight patients with MM ISS I-II (median = 59.57 $\mu \mathrm{mol} / \mathrm{L}$; range: $39.26-107.8$ $\mu \mathrm{mol} / \mathrm{L}$ ) and 13 with MM ISS III (median = $110.30 \mu \mathrm{mol} / \mathrm{L}$; range: $22.00-210.84 \mu \mathrm{mol} / \mathrm{L}$ ). The $P$ value was calculated using the Mann-Whitney $U$ test.

all these biochemical parameters. ISS stages were significantly associated $\left({ }^{*} P=0.0293\right)$ with ADO production in the BM niche (ISS III versus ISS I-II: median ADO levels $=110.3 \mu \mathrm{mol} / \mathrm{L}$ versus $59.57 \mu \mathrm{mol} / \mathrm{L}$ ) (Figure 2B).

\section{Ectonucleotidase Expression in Cells and Tissues within the BM Myeloma Niche}

Fluctuating ADO levels detected in the BM plasma of MM patients (Table 1) likely reflect the different levels of ectonucleotidase expression inside the niche. Bone biopsies from MM patients showed the presence of CD38, CD203a, CD39 and CD73 (18), helping link local ADO production to the expression of the main ectonucleotidases involved in its generation.

The spatial arrangement of ectonucleotidases expressed by representative cells of the niche (for example, plasma cells, the osteoblasts, osteoclasts and stromal cells) should reveal the existence of continuous (molecules on the same cell) or discontinuous (molecules on different cells) configurations capable of generating ADO. The CD38, CD203a, CD39, CD73 and CD26 ectonucleotidases were analyzed on primary cells from BM aspirates and osteogenic cells (osteoclasts, osteoblasts and stromal cells) from MM patients (Figure 3A-C). MM cells are $\mathrm{CD} 38^{++}$, and also express variable levels of CD39 and CD203a, while CD26 and CD73 were low or undetectable (Figure 3A). The ectonucleotidase profile of BM stromal cells (BMSC) varied according to the stage of in vitro differentiation (Figures 3B, C). Table 3 summarizes these findings and the phenotypes of representative cell lines. The distribution of ectonucleotidases confirms that CD38, CD203a and CD73, components of the adenosinergic pathways, are present in the myeloma niche: CD38 is prevalently expressed by MM cells that were also positive for CD203a at variable levels while CD73 is restricted to bone cells. It is possible that these various 


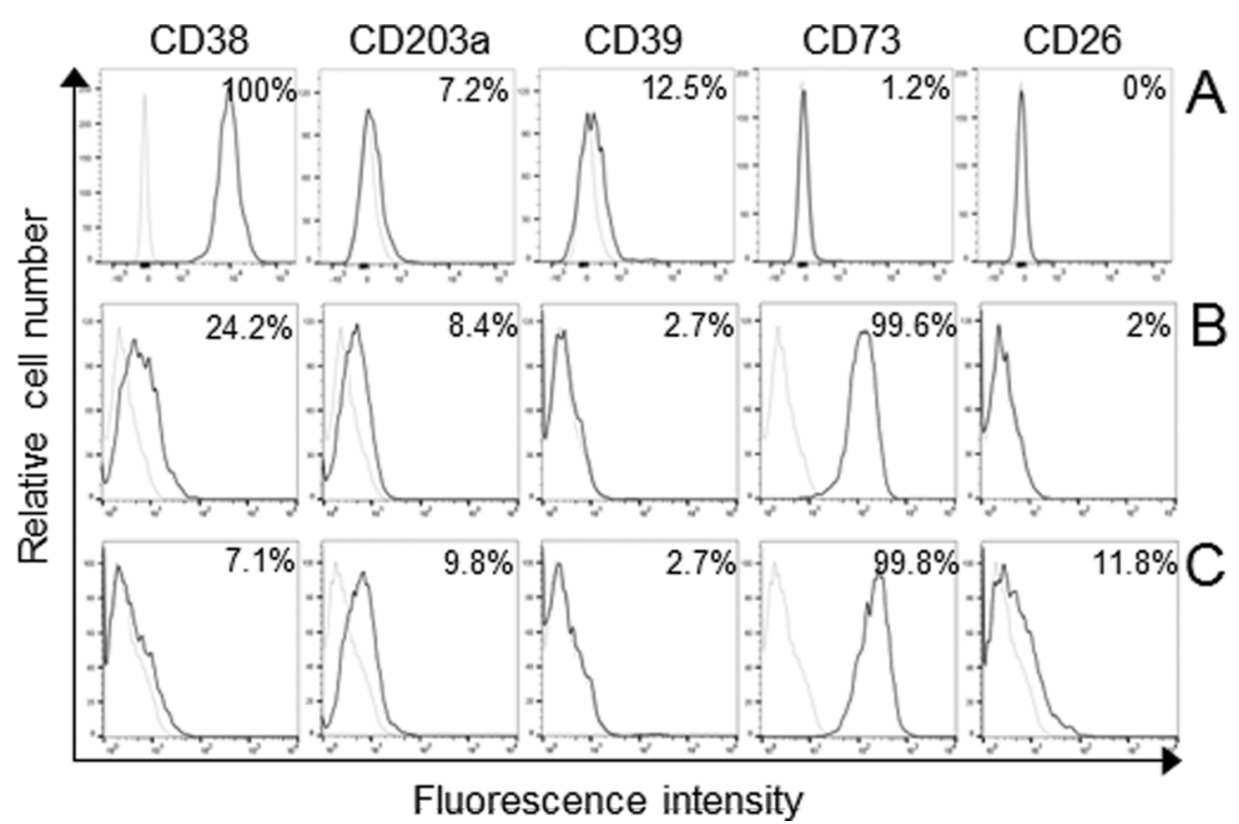

Figure 3. Expression of ectonucleotidases in cells in the BM niche. (A) Primary myeloma cells. (B) Stromal cells from cultures derived from BM aspirates from MM patients. (C) Ectonucleotidases expression after osteoblastic differentiation of mesenchymal SCs from BM aspirates from MM patients. Black peaks: marker expression levels; gray peaks: isotype controls.

Table 3. Phenotype of myeloma cells and cell lines, osteoclasts, osteoblasts and stromal cells.

\begin{tabular}{|c|c|c|c|c|c|c|c|c|c|c|}
\hline \multirow[b]{2}{*}{ Enzyme } & \multicolumn{4}{|c|}{ MM patients ${ }^{a}$} & \multicolumn{3}{|c|}{ Controls $^{b}$} & \multicolumn{3}{|c|}{ Cell lines } \\
\hline & MM & OB & OC & BMSC & OB & OC & SC & LP-1 & HS-5 & SAOS-2 \\
\hline CD38 & + & - & - & - & - & - & $+/-$ & + & - & - \\
\hline CD203a & $+/-$ & + & + & + & $+/-$ & $+/-$ & $+/-$ & - & + & + \\
\hline CD73 & $+/-$ & + & + & + & + & + & + & - & $+/-$ & $+/-$ \\
\hline CD39 & + & - & $+/-$ & - & - & - & - & - & - & - \\
\hline CD26 & - & nd & + & nd & $+/-$ & + & - & - & - & - \\
\hline TRACP ${ }^{C}$ & nd & nd & + & nd & nd & + & nd & nd & nd & nd \\
\hline
\end{tabular}

Cells from BM aspirates were stained with specific mAbs followed by FITC-labeled antimouse lg. The same was done for the multiple myeloma LP-1, stromal HS-5 and osteoblasts SAOS-2 cell lines. Phenotype was obtained by staining cells with specific mAbs followed by FITC-labeled anti-mouse Ig.

a. data from MM bone biopsies

b. data from normal bone biopsies

c. immunohistochemistry

components can be assembled into a discontinuous chain of ectonucleotidases that leads to ADO synthesis. Myeloma cells and the cellular environment are equipped with a machinery fueled by extracellular $\mathrm{NAD}^{+}$(through CD38 ${ }^{+}$cells) or ATP (through CD203a ${ }^{+}$ cells). Accordingly, ADO detected in the $\mathrm{BM}$ niche can be produced through two non-conventional, discontinuous adenosinergic networks, namely the CD38/CD203a/CD73 and the CD203a/ CD73 pathways (9).

This contrasts with the conventional continuous adenosinergic pathways we observed in normal Natural Killer (NK) cells and in pathological primary human melanoma cells $(12,19)$.
Ectonucleotidase Functionality in Cell Populations from the Myeloma Niche

The ADO levels measured in BM aspirates may reflect the functional strength of ectonucleotidase interactions with nucleotides and/or the metabolic conditions (hypoxia and acidic conditions) inside the niche. These possibilities were tested by exposing the ectonucleotidases to distinct substrates of the individual ectoenzymes involved in ADO generation.

CD38 consumes $\mathrm{NAD}^{+}$generating cADPR, ADPR and NAM (10). The activities of CD38 cyclase (cADPR formation from $\mathrm{NAD}^{+}$) and CD38 cADPR hydrolase (ADPR formation from cADPR) were measured on the human myeloma cell line LP-1, derived from an IgG- $\lambda$ myeloma (15) (Figures 4A, B). LP-1 culture supernatants reveal the presence of non-consumed $\mathrm{NAD}^{+}$, along with the expected ADPR and NAM products, confirming that myeloma cells are responsible for the enzymatic activities attributed to the native CD38 (Figure 4A). cADPR hydrolase activity is approximately 100-fold higher than the cyclase activity, which was measured using the $\mathrm{NAD}^{+}$analogue, $\mathrm{NGD}^{+}$, which has modest hydrolytic properties (20). The cGDPR product obtained accumulates in supernatants, where it is detected by HPLC (Figure 4B). The flavonoid kuromanin inhibits CD38 cyclase activity (21). Indeed, kuromanin $(100 \mu \mathrm{mol} / \mathrm{L}, 30 \mathrm{~min}$, $37^{\circ} \mathrm{C}$ ) reduced (range: $2548 \%$ ) the conversion of $\mathrm{NGD}^{+}$to $\mathrm{CGDPR}$, leaving the $\mathrm{NAD}^{+}$ hydrolytic activity unaffected (Figure 4D).

We confirmed in primary myeloma cells $\left(\mathrm{CD} 138^{+} / \mathrm{CD} 38^{+}\right)$that $\mathrm{cADPR}, \mathrm{ADPR}$ and NAM can be produced from NAD ${ }^{+}$ (Figure 4C). Therefore, primary myeloma cells must also be endowed with CD38 cyclase and hydrolase activities. Myeloma cells also express CD203a, a generator of AMP (Figure 3A). Thus, myeloma cells degraded $\mathrm{NAD}^{+}$to ADPR and then to AMP, confirming that the CD38/CD203a enzymatic tandem is functionally active. However, absent or low expression of CD73 by myeloma cells (Figure 3A) precludes the formation of detectable levels of ADO. Indeed, none of the myeloma cells isolated from BM aspirates produced enough 


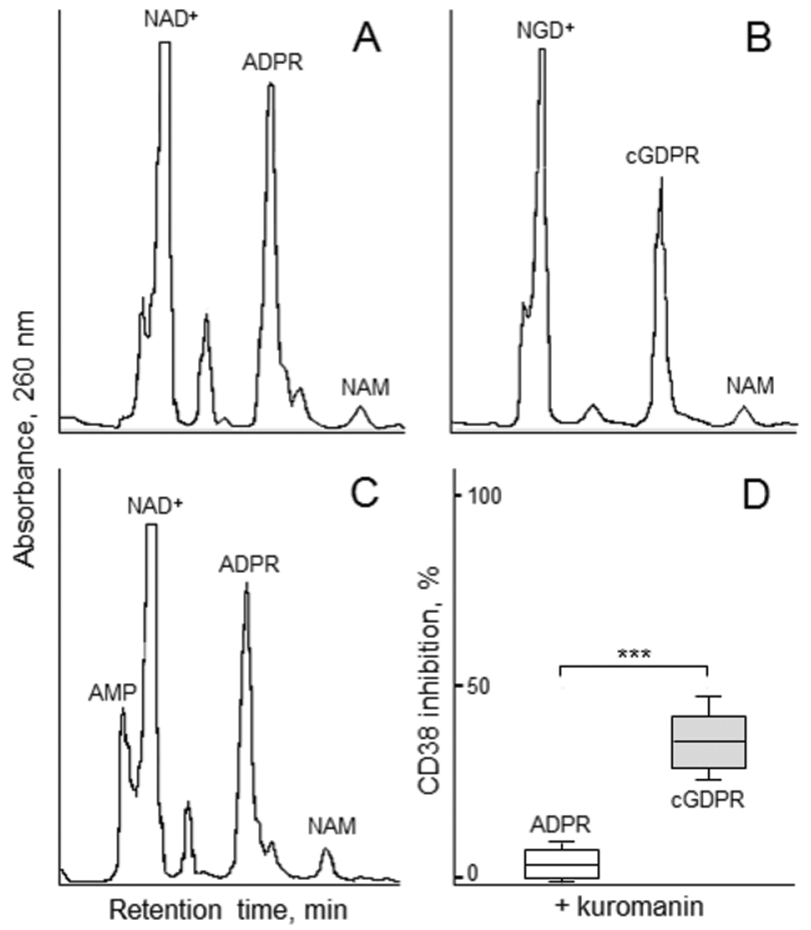

Figure 4. CD38 enzymatic functions in primary myeloma cells and the myeloma cell line. Nucleotide consumption was evaluated using MM cells $\left(2 \times 10^{6} \mathrm{cell} / \mathrm{mL}\right)$ incubated in HBSS containing NAD ${ }^{+}$or $\mathrm{NGD}^{+}(100 \mu \mathrm{mol} / \mathrm{L}$ ), in the presence of a STOP Solution (see Materials and Methods). After centrifugation, supernatants were processed for HPLC. (A) $\mathrm{NAD}^{+}$/cyclase/hydrolase activity of CD38 determined in the LP-1 myeloma cell line. Supernatants revealed the presence of non-consumed NAD $\left(R_{t}=3.0\right)$. The products derived were CADPR $\left(R_{t}=4.1\right)$, ADPR $\left(R_{t}=5.6\right)$ and NAM $\left(R_{t}=7.0\right)$. (B) CD38 cyclase activity was measured using $\mathrm{NGD}^{+}$as substrate. The breakdown of exogenous $\mathrm{NGD}^{+}$ $\left(R_{t}=3.2\right)$ in the supernatants of LP-1 myeloma cells revealed the presence of guanosine diphosphate ribose (GDPR) ( $\left.R^{\dagger}=4.2\right), \operatorname{cGDPR}\left(R_{+}=5.8\right)$ and NAM $\left(R_{+}=7.0\right)$ products. $(C)$ Primary myeloma $\left(\mathrm{CD} 138^{+} / \mathrm{CD} 38^{+}\right.$) cells produce CADPR, ADPR and NAM from NAD ${ }^{+}(a$ CD38-dependent step) and AMP (a CD203a-dependent step), confirming that the CD38/ CD203a enzymatic tandem is functionally active. The absence or low expression of CD73 precludes the formation of detectable ADO. (D) LP- 1 myeloma cells $(n=5)$ were pre-incubated with kuromanin ( $100 \mu \mathrm{mol} / \mathrm{L}, 30 \mathrm{~min}$ ) before assaying the conversion of $\mathrm{NAD}^{+}$ into ADPR or $\mathrm{NGD}^{+}$to $\mathrm{CGDPR}$. Results are expressed as percentage of inhibition of the enzymatic activity of CD38. Kuromanin reduced (range $25 \%$ to $48 \%$ ) the conversion of $\mathrm{NGD}^{+}$to $\mathrm{CGDPR}$, with no effects on $\mathrm{NAD}^{+}$hydrolytic activity. Values are the mean $\pm \mathrm{SD}$ of triplicate determinations. All data are representative of at least three experiments.

ADO to be detected by HPLC (Figure 4C). Therefore, ADO generation may be the result of heterotypic interactions among myeloma, osteogenic (osteoclasts, osteoblasts) and stromal cells. To test this possibility, we examined the contribution of locally present cells, whose synergies may lead to ADO production in the myeloma niche. Different nucleotide substrates and products were analyzed in supernatants of the myeloma cell line LP-1 (CD38 ${ }^{+} / \mathrm{CD}_{203 \mathrm{a}^{+}}$/
$\mathrm{CD}^{-} / \mathrm{CD}^{-} 3^{-}$) cultured with single or paired combinations of osteoclasts (differentiated from PBMC), osteoblasts (SAOS-2 cell line) and stromal cells (HS-5 cell line), respectively, at pH 7.4 (Figure 5, panel A).

In single cultures (Figure 5, panel B), only HS-5 cells were able to generate ADO $\left(9.17 \pm 1.5\right.$ and $10.15 \pm 2.5 \mu \mathrm{mol} / \mathrm{L} / 10^{6}$ cells) after incubation $\left(30 \mathrm{~min}\right.$ at $37^{\circ} \mathrm{C}$ ) with exogenous $\mathrm{NAD}^{+}$or ATP $(100 \mu \mathrm{mol} / \mathrm{L})$. In the presence of $\mathrm{AMP}(100 \mu \mathrm{mol} / \mathrm{L})$,
HS-5 produced the highest levels of ADO $\left(176.30 \pm 8.5 \mu \mathrm{mol} / \mathrm{L} / 10^{6}\right.$ cells $)$ of any single cell type. Therefore, stromal cells produced AMP from $\mathrm{NAD}^{+}$and ATP by CD203a, which displays a broad substrate specificity (22), while ADO was obtained via CD73. The 5'-nucleotidase activity of CD73 was uniquely responsible for AMP dephosphorylation, because the phosphatase inhibitor levamisole was uninfluential. Treatment of differentiated osteoclasts and osteoblasts (SAOS-2 line) with AMP was followed by dephosphorylation and production of ADO (42.44 $\pm 10.5 \mu \mathrm{mol} / \mathrm{L}$ and $43.40 \pm 9.3 \mu \mathrm{mol} / \mathrm{L}$ $\mathrm{ADO} / 10^{6}$ cells, respectively).

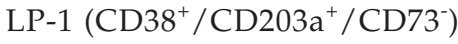
cells co-cultured with stromal cells

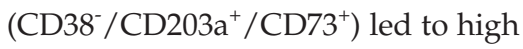
consumption of exogenous NAD ${ }^{+}, \mathrm{ATP}$ and AMP, and the production of ADO $(16.40 \pm 3.5 \mu \mathrm{mol} / \mathrm{L}, 20.70 \pm 6.3 \mu \mathrm{mol} / \mathrm{L}$ and $705.0 \pm 19.5 \mu \mathrm{mol} / \mathrm{L}$, respectively) (Figure 5, panel B). Therefore, the addition of $\mathrm{NAD}^{+}$to the myeloma-osteoblast paired combinations led to a 12.53-fold increase in ADO production, while the nucleoside levels were unmodified when myeloma cells were co-cultured with osteoclasts. When exposed to ATP, the LP-1 line co-cultured with osteoblasts (SAOS-2 cell line) and differentiated osteoclasts displayed a 4.86- and 6.41-fold increase in ADO levels, respectively. The same experiments performed with AMP showed a 3.56- and 2.06-fold increase in ADO production, respectively. (Figure 5, panel B).

It can be concluded that specific cell-to-cell contacts in the BM niche or the increased generation of ADPR (from CD38) or AMP (from CD203a), both of which substrates for ADO production contribute to an increase in ADO generation. The convergence of myeloma (CD38 high), osteoblasts (CD203a ${ }^{\text {high }}$ ) and stromal $\left(C D 73^{\text {high }}\right)$ cells supports conditions favoring ADO production and probably myeloma growth in the BM niche by tipping the balance toward the $\mathrm{NAD}^{+}$consuming CD38/CD203a/CD73 adenosinergic pathway at the expense of the canonical ATP-dependent CD39/CD73 pathway. 

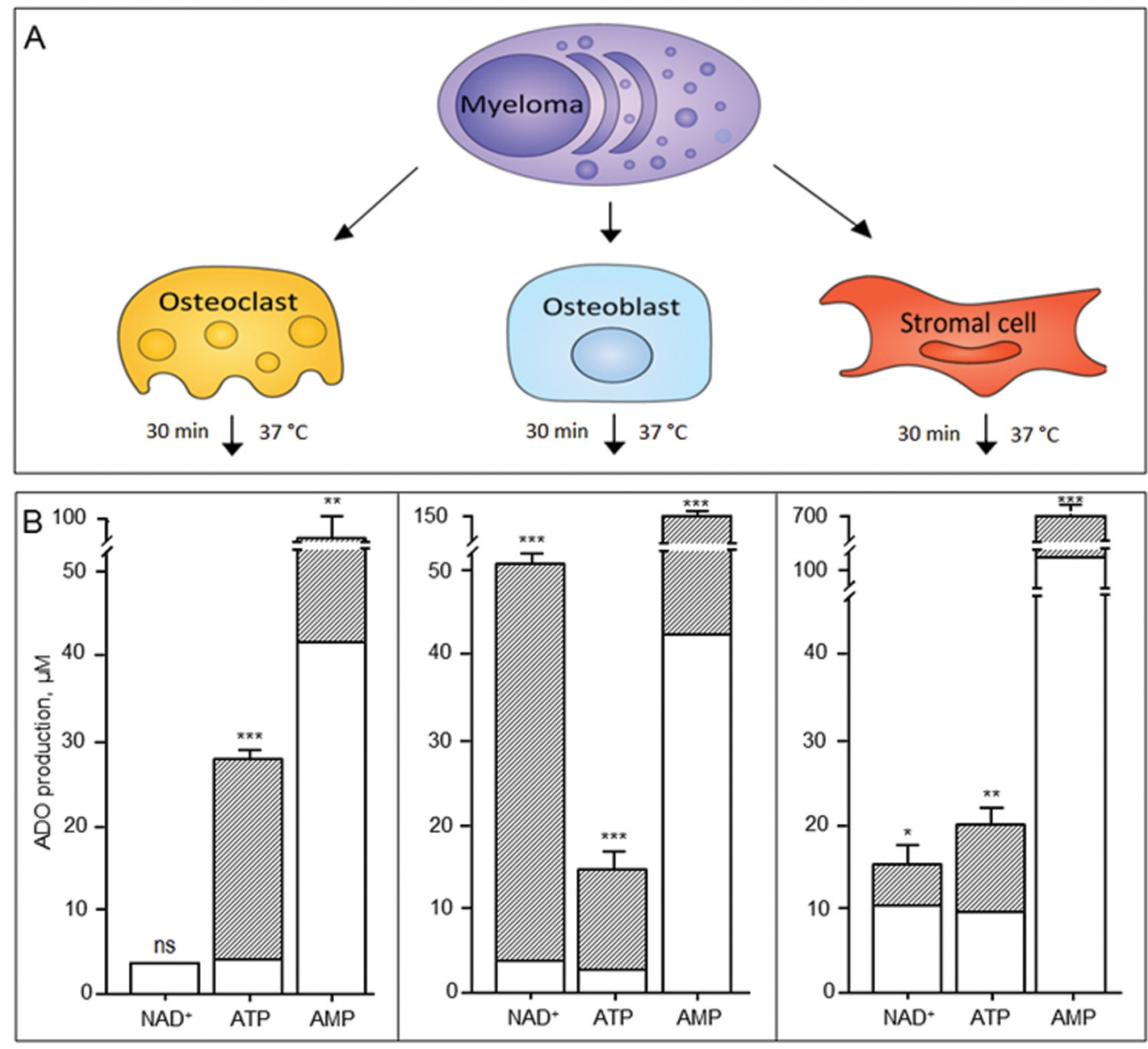

Figure 5. ADO production by mono- and co-cultures of myeloma cells with different components (osteoblasts, osteoclasts and stromal cells) of the BM niche. (A) Scheme of the co-culture system involving direct cell-cell contacts. (B) ADO generation ( $\mu \mathrm{mol} / \mathrm{L}$ ) assayed in supernatants of mono- $(\square)$ and co-cultures (四) after adding NAD ${ }^{+}(C D 38 /$ CD203a/CD73-dependent), ATP (CD203a/CD73-dependent) or AMP (CD73-dependent) for 30 min at $37^{\circ} \mathrm{C}$. Supernatants were collected and analyzed by HPLC. Variability (fold-increase) of ADO levels were detected after exposing osteoclasts (differentiated PBMC), osteoblasts (SAOS-2 cell line) and stromal cells (HS-5 cell line) to the LP-1 myeloma cells after adding NAD ${ }^{+}$, ATP or AMP. Values are the mean \pm SD of triplicate determinations. All data are representative of at least three experiments.

\section{Identification of an Alternative Pathway of Adenosine Production at Acidic pH \\ CD38 functions are highly dependent} on the $\mathrm{pH}$, and change in vivo in response to the environment. At a neutral $\mathrm{pH}, \mathrm{CD} 38$ uses $\mathrm{NAD}^{+}$as a substrate, while at an acidic $\mathrm{pH}, \mathrm{CD} 38$ catalyzes the degradation of phosphorylated $\mathrm{NAD}^{+}$ (NADP) (23).

Since the $\mathrm{pH}$ of the $\mathrm{BM}$ niche is low, the interactions between myeloma and other cells were reassessed in acidic conditions ( $\mathrm{pH} \mathrm{5.5}$, at $37^{\circ} \mathrm{C}$ ) (Figure 6). $\mathrm{NAD}^{+}$added at neutral $\mathrm{pH}$ to LP-1 cells co-cultured with differentiated osteoclasts $\left(\mathrm{CD}^{-} 8^{-} / \mathrm{CD} 203 \mathrm{a}^{+} / \mathrm{TRACP}^{+} / \mathrm{CD}^{+}{ }^{+}\right)$had no influence on ADO levels (Figure 5, panel B). However, the same co-culture performed by adding NADP (1 mmol/L) and nicotinic acid (NA, $5 \mathrm{mmol} / \mathrm{L}$ ) at an acidic $\mathrm{pH}$ produced detectable peaks of NAADP, ADPRP and a relative increase (3.8-fold) in ADO levels (Figure 6A).

Acidic conditions are paralleled by a sharp downturn in CD73 activity (24). However, TRACP, an ectonucleotidase active in acid environments and present in osteoclasts, can act as a surrogate for CD73 and may contribute to the last step in ADO production. To confirm our hypothesis, TRACP and CD73 were analyzed in differentiated osteoclasts to assess their contribution to adenosinergic pathways in the myeloma niche, in neutral and acidic conditions (Figure 6B). The adenosinergic activity was also evaluated in the presence of APCP, a CD73 inhibitor. The AMP-hydrolyzing power of TRACP was not inhibited by APCP, although it is approximately 100 -fold less efficient than that of $\mathrm{CD} 73$ at $\mathrm{pH}$ 7.4. These observations indicate that TRACP may play a co-active role with CD73 in the myeloma niche. The activation of distinct pathways leading to ADO production according to $\mathrm{pH}$ may tune the extracellular nucleotide/nucleoside balance, allowing a shift from one adenosinergic pathway to another (Figure 6C). Hence, acidic conditions make it possible to circumvent the canonical CD39/CD73 pathway, where the former enzyme works at an optimal $\mathrm{pH}$ of 8.0 (25).

\section{DISCUSSION}

This study demonstrates that immunosuppressive ADO is a soluble component of the BM myeloma niche and shows how it is locally generated. Increased concentration of ADO in the tumor milieu can be explained in part by the local metabolic context. Most activities in the $\mathrm{BM}$ niche hinge upon (i) the release of intracellular nucleotides (ATP and $\mathrm{NAD}^{+}$), (ii) the strength of their interactions with ectonucleotidases and (iii) the hypoxic conditions of the environment $(26,27)$. In this context, the nucleotides released are disassembled into ADO, which is taken up by specific ADO receptors to finetune multiple signaling pathways (28).

After verifying the presence of ADO in the myeloma niche, we turned to identifying the pathways leading to its production, to derive information useful for potential theranostic applications. Cells derived from BM plasma aspirates from patients with MM provided conclusive evidence that the canonical adenosinergic CD39/CD73 pathway of conversion of ATP to ADO is flanked by another set of ectoenzymes that leads to the same 
A

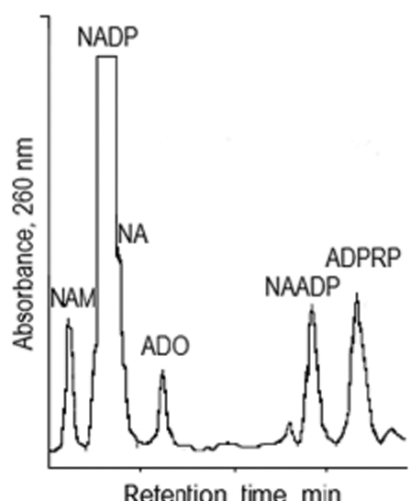

B

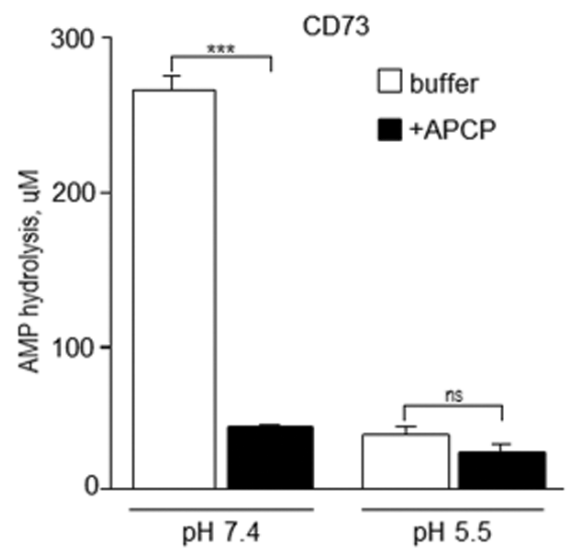

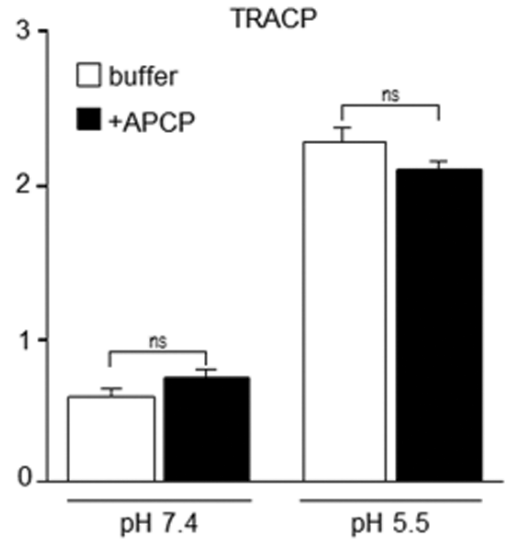

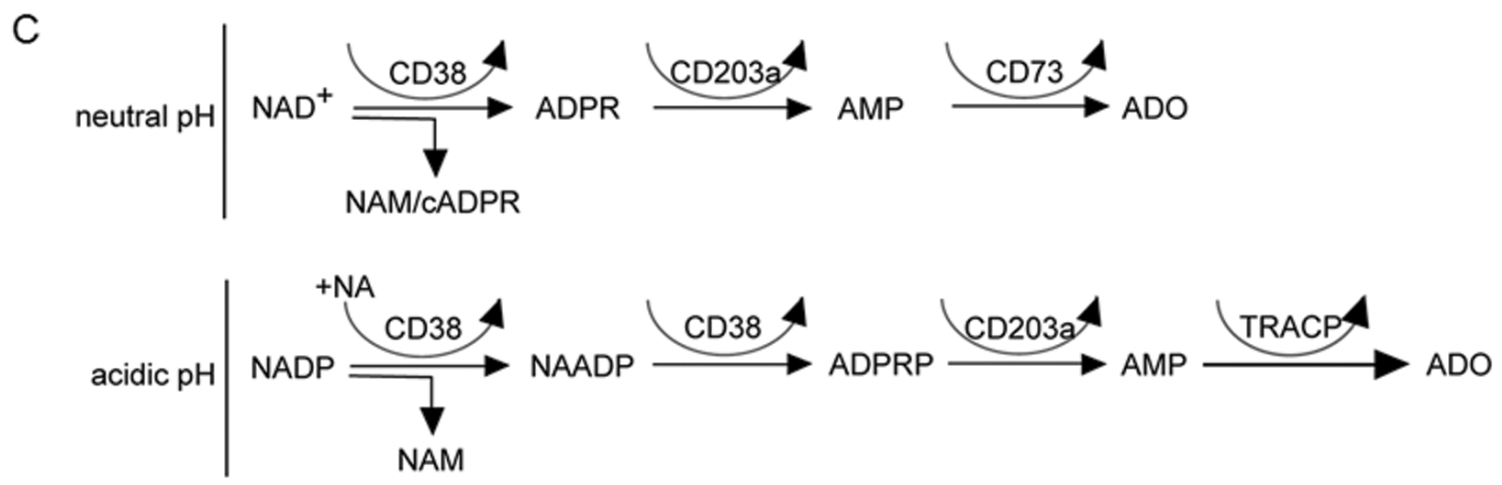

Figure 6. (A) ADO production after co-culturing the LP-1 myeloma line with osteoclasts at acidic pH. CD38 hydrolase activity at pH 5.5 catalyzes NAADP $\left(R_{t}=9.8\right)$ and $\operatorname{ADPRP}\left(R_{t}=10.8\right)$ formation from NADP ( $\left.1 \mathrm{mmol} / \mathrm{L}\right)$ and NA $(5 \mathrm{mmol} / \mathrm{L})$ substrates. The ADPRP product is then converted to AMP and finally into ADO $\left(R_{+}=8.3\right)$ by an acid-resistant phosphatase (TRACP), as determined by HPLC. (B) Adenosinergic activity of CD73 and TRACP. CD73 (left panel) and TRACP (right panel) activities were determined by HPLC at neutral or acidic $\mathrm{pH}$ after incubating osteoclasts with $100 \mu \mathrm{mol} / \mathrm{L}$ AMP for $30 \mathrm{~min}$ in the presence (or absence) of $50 \mu \mathrm{mol} / \mathrm{L}$ APCP (a CD73 inhibitor), as indicated. Enzymatic activities are expressed as the concentration $(\mu \mathrm{mol} / \mathrm{L})$ of hydrolyzed AMP. Values are the mean \pm SD of triplicate determinations. All data are representative of at least 3 experiments. (C) ADO production according to environmental pH. Abbreviations: $\mathrm{NADP}=\mathrm{NAD}^{+}$phosphorylated, $\mathrm{NA}=$ nicotinic acid, NAM = nicotinamide, NAADP = nicotinic acid adenine diphosphate, $\mathrm{ADPRP}=$ ADP-ribose-phosphate, TRACP = tartrate-resistant acid phosphatase (see text).

product, but that uses $\mathrm{NAD}^{+}$as a starting substrate. The extracellular dinucleotide is metabolized through the sequential action of the ectonucleotidases CD38, CD203a and CD73, confirming our previous observations in human $\mathrm{T}$ leukemia and melanoma lines as well as in NK cells $(9,12,19)$. These ectonucleotidases seem to operate according to their spatial configuration within a discontinuous setting, favored by the closed BM microenvironment at the interface between tumor and host cells. In fact, ADO production after adding extracellular NAD ${ }^{+}$

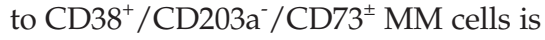

negligible. High ADO levels accumulated in the BM niche may be explained by postulating that CD38, CD203a and CD73 form functionally interrelated pathways. Indeed, CD38 is highly expressed by myeloma cells, while CD203a is detected on stromal cells. CD73 is more selectively expressed by osteoclasts, osteoblasts and stromal cells.

Co-culture experiments confirmed that myeloma cells interact with normal cells in the niche to produce ADO. In such a loop, the malignant cells apparently have instructive role(s) on the adenosinergic functionality of osteogenic cells in the BM niche, exploiting the machinery normally used to generate tolerance in the periphery. The spatial constraints of the niche play a favorable role, given the short in vivo half-life $(<10 \mathrm{~s})$ of ADO.

Contributing to the intrinsic complexity of the myeloma niche, ADO is consumed inside BM by infiltrating immune cells $(19,29)$. We previously reported that extracellular ADO acts on the AMPK checkpoint and blocks proliferation of $\mathrm{T}$ lymphocytes, reducing their ability to destroy cancer cells $(12,30)$. From this, it can inferred that the adenosinergic loop active in MM patients may favor growth 
in the BM niche by creating a safe haven from host immunosurveillance. Thus, the metabolic activities in the BM niche promoting ADO accumulation are detrimental to the immune status of $\mathrm{MM}$ patients $(31,32)$.

Another crucial factor influencing the metabolism of extracellular nucleotides in the MM niche is hypoxia, which activates a Warburg phenotype, given that the major source of cell energy depends on aerobic glycolysis (5). This leads to an accumulation of lactic acid and a reduction in $\mathrm{pH}$, a necessary condition for myeloma survival in the niche $(3,26)$.

An acidified myeloma niche provides the conditions driving ectonucleotidases to produce ADO in situ. In fact, aerobic glycolysis reduces ATP and simultaneously increases $\mathrm{NAD}^{+}(6)$. Thus, ATP may not reach concentrations high enough in hypoxic conditions to activate the canonical CD39/CD73 pathway. Instead, high $\mathrm{NAD}^{+}$activates the alternative pathway, with AMP obtained through the coordinated action of the tandem CD38/CD203a ectonucleotidases. Also highly dependent on $\mathrm{pH}$ is the CD38 enzyme (10), which is responsible for the conversion of extracellular NAD ${ }^{+}$and NADP, and whose substrate may change accordingly, as confirmed here in the supernatants of myeloma cells.

In addition, low $\mathrm{pH}$ induces a marked inhibition of ectonucleotidase CD73 activity. Indeed, isolated osteoclasts, osteoblasts and stromal cells do not produce extracellular ADO in the presence of $\mathrm{NAD}^{+}$or ATP at an acidic $\mathrm{pH}$. It is possible that TRACP, a nucleotidase regulating nucleotide receptor-mediated osteoclast functions and bone resorption in the acidic lacunas of bone (33), might contribute to ADO production as a surrogate of CD73. Indeed, our results show that ADO production under acidic conditions increases when myeloma cells are cultured in the presence of osteoclasts and after adding NADP substrate. This may indicate that the CD38/ CD203a/TRACP pathway becomes more efficient in hypoxic conditions, consuming phosphorylated $\mathrm{NAD}^{+}$at the expense of the CD203a/CD73 axis. Indirect evidence comes from the observation that acidic conditions are key factors in bone resorption, a pathognomonic feature of MM (34).

To translate these observations to the clinic, ADO levels in the BM niche of patients with MGUS/SMM were compared with the levels in patients with overt MM. In a pilot study, BM plasma from biopsies at all stages of disease was shown to contain high $\mu \mathrm{mol} / \mathrm{L}$ levels of ADO. However, median ADO levels in patients at overt stages of the disease are statistically different from asymptomatic MGUS/SMM patients, when the early phase samples are pooled.

\section{CONCLUSION}

Biomarkers from distinct biological pathways are used to improve early risks stratifications in patients with MM. Progression from earlier disease stages to full-blown MM seems to be the result of microenvironmental changes and deregulation of the immune response. Consequently, the inclusion of ADO levels in BM plasma to complement serum albumin and $\beta 2-m$ markers should be strongly considered. Current studies are underway to analyze whether plasma cell-derived microvesicles may produce ADO in the blood of MM patients $(35,36)$. The aim is to develop a novel prognostic probe for monitoring the products of ectonucleotidases in MM without the need for invasive procedures. In addition to serving as a tissue marker and an immune modulator $(10,37)$, the leading adenosinergic ectoenzyme CD38 has recently been adopted as a therapeutic target (38).

Defeating the adenosinergic properties of the tumor metabolome may increase the efficacy of therapeutic antibodies now entering in clinical use $(39,40)$.

\section{ACKNOWLEDGMENTS}

Thanks are given to A Zito for technical assistance and to L McLean for stylistic revisions. This work was supported by grants from PRIN (Ministry of Education, University, and Research, 2009 NANLST / 2012 RA5 × 3L-002) and FIRB (Fondo per gli Investimenti della Ricerca di Base, RBAP11FXBC-005) (Rome, Italy) to FM; Fondazione CRT (Turin, Italy) 2013 (2428/2014-1102) to FM; grant to Istituto Giannina Gaslini (Genova, Italy) from Compagnia SanPaolo (Turin, Italy) to VP and from Associazione Italiana per la Ricerca sul Cancro (IG2014, 15531) and Program Molecular Clinical Oncology (9965) to NG.

\section{DISCLOSURE}

The authors declare they have no competing interests as defined by Molecular Medicine, or other interests that might be perceived to influence the results and discussion reported in this paper.

\section{REFERENCES}

1. Palumbo A, Anderson K. (2011) Multiple myeloma. N. Engl. J. Med. 364:1046-60.

2. Abe M, et al. (2004) Osteoclasts enhance myeloma cell growth and survival via cell-cell contact: a vicious cycle between bone destruction and myeloma expansion. Blood 104:2484-91.

3. Harris AL. (2002) Hypoxia-a key regulatory factor in tumour growth. Nat. Rev. Cancer 2:38-47.

4. Storti P, et al. (2013) Hypoxia-inducible factor (HIF)-1alpha suppression in myeloma cells blocks tumoral growth in vivo inhibiting angiogenesis and bone destruction. Leukemia 27:1697-706.

5. Vander Heiden MG, Cantley LC, Thompson CB. (2009) Understanding the Warburg effect: the metabolic requirements of cell proliferation. Science 324:1029-33.

6. Horenstein AL, et al. (2015) NAD(+)-Metabolizing Ectoenzymes in Remodeling Tumor-Host Interactions: The Human Myeloma Model. Cells 4:520-37.

7. Quarona V, et al. (2015) Unraveling the contribution of ectoenzymes to myeloma life and survival in the bone marrow niche. Ann. N. Y. Acad. Sci. 1335:10-22.

8. Penuela S, Gehi R, Laird DW. (2013) The biochemistry and function of pannexin channels. Biochim. Biophys. Acta. 1828:15-22.

9. Horenstein AL, et al. (2013) A CD38/CD203a/ CD73 ectoenzymatic pathway independent of CD39 drives a novel adenosinergic loop in human T lymphocytes. Oncoimmunology 2:e26246.

10. Malavasi F, et al. (2008) Evolution and function of the ADP ribosyl cyclase/CD38 gene family in physiology and pathology. Physiol. Rev. 88:841-86.

11. Junger WG. (2011) Immune cell regulation by autocrine purinergic signalling. Nat. Rev. Immunol. 11:201-12. 
12. Morandi F, et al. (2015) A non-canonical adenosinergic pathway led by CD38 in human melanoma cells induces suppression of $\mathrm{T}$ cell proliferation. Oncotarget 6:25602-18.

13. Agarwal A, Ghobrial IM. (2013) Monoclonal gammopathy of undetermined significance and smoldering multiple myeloma: a review of the current understanding of epidemiology, biology, risk stratification, and management of myeloma precursor disease. Clin. Cancer Res. 19:985-94.

14. Horenstein AL, Durelli I, Malavasi F. (2005) Purification of clinical-grade monoclonal antibodies by chromatographic methods. Methods Mol. Biol. 308:191-208.

15. Pegoraro L, et al. (1989) The human myeloma cell line LP-1: a versatile model in which to study early plasma-cell differentiation and c-myc activation. Blood 73:1020-7.

16. Paiva B, et al. (2014) Multiparameter flow cytometry for the identification of the Waldenstrom's clone in IgM-MGUS and Waldenstrom's Macroglobulinemia: new criteria for differential diagnosis and risk stratification. Leukemia 28:166-73.

17. Greipp PR, et al. (2005) International staging system for multiple myeloma. J. Clin. Oncol. 23:3412-20.

18. Toscani D, et al. (2015) Expression Profile of CD38 and Related Ectoenzymes in Myeloma Bone Niche: A Rational Basis for the Use of Daratumumab to Inhibit Osteoclast Formation and Activity. In: 57th ASH Annual Meeting and Exposition. Blood, Orlando, FL, p. 2959.

19. Morandi F, et al. (2015) CD56brightCD16- NK Cells Produce Adenosine through a CD38Mediated Pathway and Act as Regulatory Cells Inhibiting Autologous CD4+ T Cell Proliferation. J. Immunol. 195:965-72.

20. Graeff RM, Walseth TF, Fryxell K, Branton WD, Lee HC. (1994) Enzymatic synthesis and characterizations of cyclic GDP-ribose. A procedure for distinguishing enzymes with ADP-ribosyl cyclase activity. J. Biol. Chem. 269:30260-7.

21. Kellenberger E, Kuhn I, Schuber F, Muller-Steffner H. (2011) Flavonoids as inhibitors of human CD38. Bioorg. Med. Chem. Lett. 21:3939-42.

22. Goding JW. (2000) Ecto-enzymes: physiology meets pathology. J. Leukoc. Biol. 67:285-311.

23. Graeff R, Liu Q, Kriksunov IA, Hao Q, Lee HC. (2006) Acidic residues at the active sites of CD38 and ADP-ribosyl cyclase determine nicotinic acid adenine dinucleotide phosphate (NAADP) synthesis and hydrolysis activities. J. Biol. Chem. 281:28951-7.

24. Yegutkin GG. (2014) Enzymes involved in metabolism of extracellular nucleotides and nucleosides: functional implications and measurement of activities. Crit. Rev. Biochem. Mol. Biol. 49:473-97.

25. Leal DB, et al. (2005) Characterization of NTPDase (NTPDase1; ecto-apyrase; ectodiphosphohydrolase; CD39; EC 3.6.1.5) activity in human lymphocytes. Biochim. Biophys. Acta. 1721:9-15.

26. Vaupel P, Mayer A. (2016) Hypoxia-Driven Adenosine Accumulation: A Crucial Microenvironmental Factor Promoting Tumor Progression. Adv. Exp. Med. Biol. 876:177-83.
27. Sitkovsky M, Ohta A. (2013) Targeting the hypoxia-adenosinergic signaling pathway to improve the adoptive immunotherapy of cancer. J. Mol. Med. (Berl) 91:147-55.

28. Fredholm BB, AP IJ, Jacobson KA, Linden J, Muller CE. (2011) International Union of Basic and Clinical Pharmacology. LXXXI. Nomenclature and classification of adenosine receptorsan update. Pharmacol. Rev. 63:1-34.

29. Reagan MR, Ghobrial IM. (2012) Multiple myeloma mesenchymal stem cells: characterization, origin, and tumor-promoting effects. Clin. Cancer. Res. 18:342-9.

30. Buque A, et al. (2016) - Trial Watch - Small molecules targeting the immunological tumor microenvironment for cancer therapy. Oncoimmunology 5.

31. Chillemi A, et al. (2014) CD38 and bone marrow microenvironment. Front. Biosci. (Landmark Ed) 19:152-62.

32. Cekic C, Linden J. (2016) Purinergic regulation of the immune system. Nat. Rev. Immunol. 16:177-92.

33. Kaunitz JD, Yamaguchi DT. (2008) TNAP, TrAP, ecto-purinergic signaling, and bone remodeling. J. Cell. Biochem. 105:655-62.

34. Utting JC, Flanagan AM, Brandao-Burch A, Orriss IR, Arnett TR. (2010) Hypoxia stimulates osteoclast formation from human peripheral blood. Cell Biochem. Funct. 28:374-80.

35. Chillemi A, et al. (2015) Generation and characterization of microvesicles after daratumumab interaction with myeloma cells. In: 57 th ASH Annual Meeting and Exposition. Blood, Orlando, FL, p. 1849.

36. Rak J. (2015) Cancer: Organ-seeking vesicles. Nature 527:312-4.

37. Kumar S, Kimlinger T, Morice W. (2010) Immunophenotyping in multiple myeloma and related plasma cell disorders. Best Pract. Res. Clin. Haematol. 23:433-51.

38. van de Donk NW, et al. (2016) Clinical efficacy and management of monoclonal antibodies targeting CD38 and SLAMF7 in multiple myeloma. Blood 127:681-95.

39. Lonial S, Durie B, Palumbo A, San-Miguel J. (2016) Monoclonal antibodies in the treatment of multiple myeloma: current status and future perspectives. Leukemia 30:526-35.

40. Young A, Mittal D, Stagg J, Smyth MJ. (2014) Targeting cancer-derived adenosine: new therapeutic approaches. Cancer Discov. 4:879-88.

Cite this article as: Horenstein AL, et al. (2016) Adenosine generated in the bone marrow niche through a CD38-Mediated pathway correlates with progression of human myeloma. Mol. Med. 22:694-704. 